\title{
Boundary Management and Communication Technologies
}

\author{
Marta E. Cecchinato ${ }^{1}$, Anna L. Cox $^{2}$ \\ ${ }^{1}$ Northumbria University, ${ }^{2}$ University College London
}

\begin{abstract}
We live in a world of communication overload, where there is a wide range of platforms and devices to choose from, each providing massive content, offering different affordances, and fighting for our attention. Mobile technologies have contributed to expectations of anywhere anytime connectedness, making it hard for individuals to switch off. As a result, it can be hard to feel truly disconnected from work. A lack of control over work-home boundary cross-overs and interruptions can reduce post-work recovery, reducing productivity and increasing stress. Technology is not inherently good or bad, but rather, the way it is adopted and used can positively or negatively colour one's experience. As such, in this critical review we take a social constructionist approach to emphasise how communication technologies are challenging as well as supporting work-home boundary management. In doing so, we bring together work from occupational psychology (boundary theory) and human-computer interaction (computer-mediated communication and crossdevice interaction). Understanding how these aspects interact and influence each other is important in order to support individuals appropriately, inform policies and guidelines, and ensure both social and digital interactions are designed carefully.
\end{abstract}

\section{Introduction}

The growing number of mobile communication technologies and computer-mediated communication (CMC) platforms has brought numerous benefits to and enrichments of the way we work and socialise. However, they also lead to the challenge of being always 
connected, which can be a source of stress (Barley, Meyerson, \& Grodal, 2011). The extent to, and the ways in, which digital technologies foster stress, especially in relation to workhome boundary management, has been of particular interest in occupational psychology and to a lesser extent in human-computer interaction. Understanding this relationship has important implications for improving workplace wellbeing. In fact, work-related stress is a major health problem in the work environment, costing over $£ 5$ billion a year just in the UK (HSE, 2017).

Most work looking at how workers are affected by this constant connection to platforms and devices belongs to the field of occupational psychology, where efforts have been directed towards understanding work-home boundary management practices and developing boundary theory (e.g., Ashforth, Kreiner, \& Fugate, 2000; Kossek, Ruderman, Braddy, \& Hannum, 2012; Rice, 2017). In contrast, work investigating the ways in which ubiquitous technology is changing our way of working comes primarily from the field of human-computer interaction (HCI), where there is a large body of work looking at computer supported mediated work and availability management (Cecchinato, Cox, \& Bird, 2017; Mazmanian \& Erickson, 2014). While the two fields complement each other nicely, there is still little research that focuses on how the two overlap. In this chapter, we present a critical review (Grant \& Booth, 2009) of the literature from occupational psychology and HCI to create an up-to-date understanding of how communication technologies are affecting workhome boundary management.

The social construction of technology (SCOT) approach guides our review to explain how users experience work-home boundaries and their use of technology, as a result of interactions that define the experiences. This means, rather than relying on a false dichotomy that technology can be good or bad, SCOT researchers have shown how there is a two-way 
relationship in how technology is influencing society and vice-versa, otherwise known as “interpretive flexibility” (Klein \& Kleinman, 2002). Kalman (2016, p. 9) explains that, "[i]t is not the use of ICTs that blurs the boundaries between work and home, but rather the managers, colleagues or clients who expect work to be carried out at home (or family and friends who expect employees to divert attention to them during the workday)". Similarly, individuals co-construct, manage and negotiate boundaries around their roles through social interactions. As Kreiner, Hollensbe and Sheep (2009) point out, boundary theory offers an ideal lens to study work-home boundaries within the social-constructionist approach. Our review focuses on the role that communication technologies play in shaping boundary management. As such, we emphasise how the relationship between individuals and technology can bring both enrichment and challenges, and by doing so, we are able to unearth strategies that can help individuals and organisations around boundary management.

We start by covering how boundary research has evolved over time and in response to changes in technology, and then explain how mobile devices have shifted work outside the office (and family issues inside the office) through a proliferation of devices and CMC platforms that can support and challenge boundary management, negotiation, and availability. With particular focus on how this impacts knowledge workers (Pyöriä, 2005) who have flexible working practices, we start by reviewing boundary theory to explain work-home conflicts and enrichment. We then reflect on how these have changed as new communication technologies have been introduced. Finally, we conclude with an assessment of boundary management strategies that can be applied top-down and bottom-up to show how policy makers, practitioners and individuals can support better boundary management. Understanding these aspects can help researchers guide future work on boundary 
management in the digital age, and practitioners know where to focus efforts when designing interactions with communication technologies.

\section{Terminology}

As this chapter brings together research from different fields, we clarify key terms in our review, namely what we mean by "boundary management" and "communication technologies". We refer to boundary management as any practice that an individual puts in place when creating, negotiating, and maintaining boundaries around work and home. Boundary theory literature does not agree on the terms used to describe the domains around the boundaries: as Allen (2013) points out, the terms work vs. home, work vs. family, and work vs. life are often used interchangeably to cover the variety of life roles. Here, we choose to use the umbrella expression work-home boundaries and to juxtapose work vs. personal to broadly differentiate between life roles and domains that are not necessarily confined to a specific time or space. For a deeper discussion around this terminology, see Moen (2011).

From an HCI perspective, we use communication technologies as an umbrella term that encompasses both communication platforms (e.g., email, WhatsApp) and communication devices (e.g. smartphones, laptops). To simplify, while the former refers to the software or applications, the latter represents the hardware through which we can communicate. In particular, rather than "channel", which can refer to the device or medium in communication research, we use the term "platform" to refer to the means by which one accesses content or communication.

\section{Work-home Boundaries}

Over the past 20 years, popular media have reported the growing interest in "worklife balance", or the ideal equilibrium of wellbeing in all aspects of one's life (Kreiner et al., 2009), as the outcome of a more complex process of work-home boundary management. The 
idea of balance is rooted in balance theory, as first described by Fritz Heider (1946). When people perceive important aspects of their life as being part of a system, they are inclined to maintain a state of balance among these elements, often through a "a juggling act", where "some balls (roles) are larger (more demanding), some weigh more than others" (Roche, 2015, p. 18). How we juggle all these roles depends on many factors, some of which can have a positive impact on work-life balance (e.g., job satisfaction, telework), while others can impact it negatively (e.g., work overload and job demands).

\section{Boundary Theory}

In general, boundaries are delimitations of an area, which can refer to a physical space (e.g., a country, a home), or a more abstract domain (e.g., a role). When referred to work and personal domains, boundaries have been classified as physical, temporal, or psychological (Clark, 2000). Physical boundaries for example can be the walls of an office, or a dedicated desk in the home of a telecommuter. Temporal boundaries refer to strict schedules, like a nine to five job, and/or explicit transitions between working time and family time, such as using the commute to shift and detach from one role to another. Finally, psychological boundaries are the series of rules self-created to establish which behaviours and attitudes belong to which domain and preferences for the balance among the domains.

Boundaries can be conceptualised along an integration-segmentation continuum (Ashforth et al., 2000). At one end of the continuum are individuals who tend to have work and home domains fully integrated, where "home" and "work" are "one giant category of social existence, for no conceptual boundary separates its contents or meaning” (Nippert-Eng, 1996, p. 567). At the other end are those for whom work and home are perceived as two completely separated worlds. Kossek, Ruderman, Braddy, and Hannum (2012) describe three main boundary styles that extend the integration-segmentation continuum paradigm, and 
include: separators, volleyers, and integrators. While integrators and separators reflect behaviours of those at the two extremes of Ashforth's continuum, volleyers are people who rely on both strategies and switch between them depending on job structure and family situation (Kossek, Baltes, \& Matthews, 2011).

On a daily basis, individuals can experience repeated shifts between the different roles in different domains, each having different responsibilities and resources (e.g., employee and parent). These shifts are known as a "micro-role transitions" (Ashforth et al., 2000) and happen, for example, when a parent receives a phone call or email from their child's school while at work. Ashforth, Kreiner and Fugate (2000) distinguish them from "macro-role transitions", where these shifts are less frequent and occur more generally within the same domain from an old role to a new role, which comes with new responsibilities and resources (e.g., moving from being a $\mathrm{PhD}$ student to becoming a faculty member).

The nature of the boundaries (physical, temporal, or psychological) and the degree of permeability to which they allow cross-overs (or micro-role transitions) has been attributed as the result of three factors: (1) identity centrality, (2) perceived sense of control (Kossek et al., 2012), and (3) the importance of work norms (Park, Fritz, \& Jex, 2011). These, along with boundary strategies (which will be discussed at the end of the chapter), make up one's boundary management style (Kossek et al., 2012).

Identity centrality. Grounded in identity theory, identity or role centrality is an indication of the value that an individual puts on each of his or her roles and reflects the time and energy invested in a role. Identity centrality can be of four types: work, family, dual, or other (e.g., where priority is given to hobbies).

Perceived boundary control. This refers to a sense of control over how permeable boundaries are and it is a psychological interpretation rather than a personal trait. Perceived 
boundary control can be high or low. People with high boundary control feel they are in control of when, how often, and in which direction boundary crossings occur, based on their role demands and centrality. Contrarily, people with lower boundary control perceive lower agency around boundary spill-overs and are more likely to experience work-family conflict. Kossek et al. (2012) found that boundary control is negatively correlated with role conflict and stress and suggested that regardless of one's preference for integration or segmentation, what makes the difference in boundary management satisfaction is a sense of boundary control.

Work norms. Because of its basis in social-constructionism (i.e., the idea that boundaries are constructed in relation to others), an individual's integration-segmentation behaviour has been found to be consistent with segmenting norms in their workplace (Park et al., 2011). That is to say, if a person experiences high segmentation in their organisation, he or she will be more likely to adopt a more segmented boundary style, for example by not check work emails outside of working hours. Similarly, there may be a certain expectation of how one might integrate or segment, sometimes accompanied by company policies or guidelines.

\section{Work-home Conflict}

Each role of an individual comes with its own expectations of time, attention, and resources. However, these many roles may often conflict with each other. "Work-life conflict occurs when the role demands in one domain interfere with meeting the demands of a role in another domain" (Olson-Buchanan \& Boswell, 2006, p. 436). Such conflict has been linked to several undesirable outcomes, such as burnout, absenteeism, and stress (Amstad, Meier, Fasel, Elfering, \& Semmer, 2011; Greenhaus \& Powell, 2006; Kreiner et al., 2009). Just like different roles have different expectations, also different environments like work and home 
have strong (but often contrasting) expectations around rules, behaviours, and attitudes (Clark, 2000). The tensions, the interactions, and the management strategies thus created around the role/environment border are an interesting area of investigation still underexplored.

Researchers (Ashforth et al., 2000; Hall \& Richter, 1988) have suggested that more integration of work and home can lead to negative consequences. For example, the permeability of an integrated role allows interruptions, which in turn leads to increased confusion as to what role to adopt at that moment. This implies that individuals with higher integration have more difficulty disengaging from different roles when in a specific domain, causing negative affect and less task enjoyment (Williams, Suls, Alliger, Learner, \& Wan, 1991). This is especially true if we think about ubiquitous technology that, for example, allows work communication to interrupt family time on a Sunday evening, or vice-versa, personal emails to be sent to a work account while in the office. Those who sit on the integration end of the continuum might be more likely to respond to a work email received out of office hours, interrupting their personal life; and the opposite scenario is just as likely (Ashforth et al., 2000).

Interruptions can also challenge those who have more segmented boundaries and roles. As Olson-Buchanan and Boswell (2006) point out, those with segmented roles have a more negative reaction, feel more strained, and experience more inter-role conflict when an interruption occurs, compared to individuals with more integrated roles. Let's take the example of receiving a work email outside of working hours: while for those who prefer to integrate it can help them keep on top of work, for those who prefer to segment work-home boundaries it can be a source of stress because they find it harder to ignore the work message during non-work time (Cecchinato, Cox, \& Bird, 2015b; Pielot, Church, \& de Oliveira, 
2014). This role-referencing can result in mental preoccupation with another role, leading to strain-based work-home conflict (Olson-Buchanan \& Boswell, 2006).

While it is important to understand that cross-role interruptions and spill-overs can occur for both integrators and separators, it is even more important to remember that these conflicts have a bi-directional nature, meaning work can interrupt non-work and non-work can equally disrupt work, depending on which role one choses to engage in (Greenhaus \& Powell, 2006; Kossek et al., 2012; Kreiner et al., 2009).

\section{Work-home Enrichment}

Not all role-referencing and spill-overs have negative effects. Greenhaus and Powell (2006) propose a model of Work-Family Enrichment in which work and family are allies, and the enrichment comes from "the extent to which experiences in one role improve the quality of life in the other role" (Greenhaus \& Powell, 2006, p. 73). The authors offer an extensive review on prior work measuring work-home enrichment and identify: (i) five resources that can promote work-family enrichment (skills and perspectives, psychological and physical resources, social-capital resources, flexibility, and material resources); (ii) two mechanisms through which resources promote enrichment (performance, and affect); and (iii) several moderators that determine conditions for resources in one role to enrich another role (salience of role, perceived relevance of resources, and consistency of resources with norms and requirements).

As with work-home conflict, work-home enrichment also has a bi-directional nature. One of the five resources, flexibility, is of particular relevance. Flexibility is the ability to determine location, timing, and pace with which role requirements are met; communication technology enables us to achieve such flexibility, but also may impose too much flexibility 
and obligations. In the next section we will analyse how affordances and features of communication technologies are affecting work-home boundaries.

\section{How Aspects of Communication Technologies Affect Work-Home Boundaries}

Digital technologies increase flexibility by enabling employees to access their work and of their personal life anytime and in any place (Allen, 2013; Boswell \& Olson-Buchanan, 2007). They do so by shifting where we can work, which in turn defines how multi-device ecologies are used, by shaping what work or personal role we convey through ecologies of communication platforms, and finally by challenging the expectations and awareness of one's availability around work or personal domains.

\section{Work Place and Space Shift}

Mobility as an affordance of communication technology (Axtell, Hislop, \& Whittaker, 2008; Rice et al., 2017) can shape and determine how, for example, teleworkers do their job (Brown \& O’Hara, 2003). There are several interpretations around what constitutes mobility, ranging from contrasting the static or mobile location of where a computer can be situated in the physical space (e.g., a desktop PC can only be on a table, whereas a mobile phone can be carried in a pocket everywhere) (Oulasvirta, Petit, Raento, \& Sauli, 2007), to more abstract interpretations that refer to mobility as the ability to move across space and time through a mobile device for work or personal reasons (Cousins \& Robey, 2015).

Today's workspace is distributed across multiple artefacts and locations, which yield to trends in device specialisation, parallelism, and fragmentation (Santosa \& Wigdor, 2013). This device specialisation is not just limited to work spaces but also involves the home. Devices are used differently depending on where they are used and for what reason. Kawsar and Brush (2013), looking at how multiple devices were used in the home, identified spatial and temporal habits of common Internet activities. In terms of location, more personal 
activities (e.g., social networking) took place in private spaces (e.g., the bathroom) where interruptions are less acceptable and less likely to happen. More public and shared spaces (e.g., kitchen) instead were used for work purposes, as well as personal reasons.

To make sense of mobility and what it means for work-home boundaries, it is useful to rely on Harrison and Dourish's (1996) distinction between space and place, where the former is defined as a physical location and the latter prescribes behaviours for a specific space. More simply, spaces become places through the social interactions that happen in them. For workers with flexible working patterns, communication technology has made it more complicated to distinguish between different places. Thinking about Kawsar and Brush's (2013) findings, the same space or locale (e.g., a kitchen) becomes populated with different places (e.g., an office space to work, but also an eating area for the family). Such places have temporal properties: "the same space can be different places at different times" (Harrison \& Dourish, 1996, p. 7). What happens when those different times overlap or are not clearly defined?

More than twenty years later, we question what happens when digital spaces and physical spaces are collocated, and particularly when they define incongruent work and personal places with overlapping temporal properties. Multi-device interaction has in fact created distributed workspaces, defined as "virtual areas spanning multiple devices across all physical working locations" (Santosa \& Wigdor, 2013, p. 63). Kawsar and Brush's insights are interesting and novel but not as discerning as they could have been, for example taking Dourish's (2006) distinction between space and place. For example, what happens when digital and physical places overlap and create work-home conflict? How can interactions with technology, especially for distributed workspaces, be better designed to avoid such conflicts? 
Before mobile technologies were introduced in our everyday lives, boundaries between work and home were more defined. Today, 77\% of Americans own a smartphone, 51\% own a tablet (Pew Research, 2018), 5\% own a smartwatch (The NPD Group, 2017), and these numbers are growing. Thus, understanding user interactions across multiple devices has become an active area of research, especially in more recent years. Bødker and Klokmose talk about all the devices "that a person owns, has access to, and uses" as "device ecologies" (Bødker \& Klokmose, 2012, p. 448), and argue how these are constantly changing and adapting to the environment and the user. How combinations of devices are chosen and used for specific purposes needs to be understood, especially if this is different for work and for personal reasons, thus affecting boundary management.

When Blackberries became widespread, work-related emails got pushed to recipients' pockets, rather than being stored for later retrieval, providing an always-online experience and contributing to the addictive effect email can have on mobile devices (Mazmanian, Yates, \& Orlikowski, 2006; Turel \& Serenko, 2010). Once smartphones, like the iPhone, became popular, Dery, Kolb and MacCormick (2014) noticed that people used mobile phones mostly for personal use and associated BlackBerrys instead only with work. This meant that many users relied on two devices to keep boundaries separate between home and work, as Cousins and Robey also identified (2015). This is one strategy that people may adopt to disconnect from work outside the office.

However, mobile devices (laptops, smartphones, and tablets) also constitute a bridge across work and personal boundaries, as Dearman and Pierce (2008) and Fleck, Cox and Robison (2015) found. Karlson, Meyers, Jacobs, Johns and Kane (2009) looked specifically at multi-device use and the impact on boundaries and working time. Their data logs and follow-up interviews showed that participants accessed work email outside working hours 
and relied on their phone whenever they did not have access to a PC. They found that people in their sample preferred to be constantly connected with work and life domains through their mobile phones and emails, as this connectedness gave participants a stronger sense of perceived control. These findings support Greenhaus and Powell's (2006) idea of workfamily enrichment, and the importance of perceived boundary control supported by Kossek et al. (2012).

More recently, device ecologies have started to include also wearable technology, such as smartwatches. In contrast to mobile devices that can be placed in pockets and bags, wrist-worn devices are always in contact with its user and as such can be more discreet, allowing minimal interference between the user and the task, but at the same time they can also be more disruptive, as they are both "always on" in function as well as "always on the user". Therefore, smart wrist-worn devices introduce the opportunity to explore new research areas of mobile user experience in relation to boundary management. So far, very little work has looked at this, with one exception. Cecchinato and colleagues (Cecchinato \& Cox, 2017; Cecchinato, Cox, \& Bird, 2015a; Cecchinato et al., 2017) analysed how smartwatches are used within device ecologies and how they impact boundary management. We found that smartwatches are used strategically to better manage notifications and filter important messages to the wrist, as well as to help individuals manage their availability to others, by leveraging the limited functionalities and the material properties of the watch. For example, users would rely on the act of taking off the watch at home or at the end of the day as a ritual to help them disconnect from their work day.

The next section moves from devices to platforms to analyse how they impact workhome boundaries, particularly when it comes to portraying ourselves and our availability through CMC. 


\section{Using Multi-platform Ecologies for Work and Personal Roles}

The typical individual enacts several roles throughout the day, such as parent, colleague, friend, employee, etc., none of which exists in a vacuum. How we choose to use CMC platforms tells something about how we decide to portray ourselves to others and could help inform how technology helps co-construct and negotiate work-home boundaries (Diaz, Chiaburu, Zimmerman, \& Boswell, 2012).

Goffman's (1959) dramaturgical approach offers a lens to understand how users might decide to portray themselves. Goffman builds on the idea that most behaviours are bounded in space and time, and guided by specific norms belonging to the context. Farnham and Churchill apply this to the digital and physical self and call this "faceted identity", where “different aspects of identity are performed depending on context, and expect that identity faceting will vary depending on the individual” (2011, p. 2). Similarly, Nippert-Eng discussed how self and identity are negotiated around time and space, when discussing what constitutes "work" and "home": We each make "some sort of distinction between who we are when we are 'at work' and 'at home'. This distinction may be quite remarkable for some (currently segmenting) people, hardly noticeable for other (extremely integrating) ones. However different our home and work selves are, though, boundary work supports these variations in who we are" (Nippert-Eng, 1996, p. 569).

Market predictors have seen, and expect, a strong growth in the use of mobile devices for any form of communication. Use of email on phones used to be an exception, done primarily when fully-featured computers were not available, but as work becomes more flexible, its use "on-the-go" is more popular and accepted: approximately $50 \%$ of email users access it on their mobile devices (Radicati Group, 2015b; Specht, 2018). Instant messaging 
accounts, which today are over 3.2 billion, are expected to grow at a 4\% rate until 2019 , particularly for business use compared to personal use (Radicati Group, 2015a).

CMC platform can be used for work purposes, personal reasons, or both, and the reason may be influenced by the device they are accessed on. The ways in which people use communication technologies is rapidly evolving (Dery et al., 2014) and communication in the workplace has become particularly challenging compared to personal communication because it is becoming "more acceptable to have informal, non-informative, and non-work related (e.g., personal) conversations via an instant message service or with mobile devices in the workplace" (Cho, Ramgolam, Schaefer, \& Sandlin, 2011, p. 40; Fortunati, 2002). In fact, while work communication is fragmented across different devices, it is now also distributed across a growing number of platforms, which go beyond just email and include for example instant messaging (e.g., Skype, Slack, WhatsApp) and social media (e.g. Facebook and Workplace by Facebook). As a result, some argue that we live in a world of communication overload (Cho et al., 2011), where the rate and quantity of messages sent and received over a growing number of devices and platform can make it harder for individuals to process them.

Despite the fragmentation of platforms, previous work has identified a trend for strong curation of communication around different platforms, in order to keep work and personal exchanges separate. This behaviour can be associated with a desire to better manage work and personal boundaries, as well as to improve retrieval of information (Cecchinato, Sellen, Shokouhi, \& Smyth, 2016). Recently, Nowens, Griggio, and Mackay (2017) suggested that users may create idiosyncratic communication "places" within the "space" of the same app (using Harrison and Dourish's (1996) definitions), adjusting rules based on the person they are communicating with. In other words, each platform (i.e., space) is associated with different rules (i.e., making it a particular place) and these rules are personal to the 
users, rather than inherent in the communication app. For example, the authors report the case of a participant who is friends with a colleague, so whenever he wants to contact the colleague for non-work purposes he will use Facebook Messenger, but he would not use WhatsApp because he sees it as a too personal platform. Other researchers have specifically compared different communication platform such as Facebook vs. Gmail (Shen, Brdiczka, \& Ruan, 2013) or WhatsApp vs SMS (Church \& de Oliveira, 2013) and found similar results. When the rules for a particular platform are not respected by others, work-home boundary conflict can occur. Cecchinato, Cox and Bird (2015b) report the case of a participant whose friends and family would email her on her work account when she is in the office instead of using what she would consider a personal platform (e.g., her personal account) because they know she is more likely to see the message in a timely manner. These examples emphasise how the context of a communication platform, the personal preference for use, as well as how it used in relation to others, can affect work-home boundary management.

Given this fragmentation of platforms used for work and personal communications and the risks that might arise for work-home boundary management, users have developed or socially constructed new habits across devices and channels, and it is through these new habits that work-home boundary management can be further challenged or enriched. For example, Matthews, Pierce, and Tang (2009) found that users preferred their phone to triage messages in the inbox because they could easily swipe to delete or archive emails, while fully featured computers were used for reading and replying to emails, especially work ones. They also observed that smartphones were used to maintain awareness of information while away from a computer, e.g., by checking emails from remote collaborators. Other researchers have found that these checking or monitoring activities happen primarily outside of working hours, such as early morning or evening, or at weekends (Kawsar \& Brush, 2013), reinforcing the 
notion that smartphones have the ability to blur work-home boundaries, depending on how available one decides to be.

\section{Expectations of Work and Personal Availability}

The use of communication technologies can have a positive effect, increasing work satisfaction (Diaz et al., 2012) and empowering users to work where and when they feel is best, for example shifting an activity to a "dead time" to relieve pressure of availability (Bittman, Brown, \& Wajcman, 2009). However, it also facilitates the blurring of boundaries (Boswell \& Olson-Buchanan, 2007), increasing vulnerability to work-home conflict. As a result, it is more difficult for employees to distance themselves from work during nonworking time (Park et al., 2011); that is, work-family boundary management tends to be asymmetric (Rice, 2017). It is worth noting that unlike personal life, which is not necessarily bound in time, work life is generally confined within certain hours, even if these are flexible and fragmented throughout the day. As a result, the challenges of constant availability for work can have worse implications compared to personal and indeed have been associated with stress and burnout (e.g. Amstad et al., 2011; Kossek et al., 2012). However, while this phenomenon is more salient in the work context, it also applies to personal life, whereby friends and family still expect timely responses (O’Hara, Massimi, Harper, Rubens, \& Morris, 2014) causing role conflict in the individual, who has to more frequently complete micro-role transitions. In this section we will first analyse the challenges of expecting availability, before we move on to how curating others' awareness of one's availability and unavailability can help regain control over work-home boundary cross-overs.

Managing availability after working hours can be so challenging, some refer to it as "the new night shift", where employees log back into work platforms (or never log out) to respond to messages (Boswell, Olson-Buchanan, Butts, \& Becker, 2016). When this constant 
connectivity is not motivated by the individual's gains, it is generally the result of social expectations and work pressures (Barley et al., 2011). As a result, an individual may feel expected to be more attentive and responsive to incoming messages. Motivated by the desire to understand temporal patterns of responses in asynchronous CMC, Kalman and Rafaeli (2005) analysed chronemics (i.e., the role of time in communication) in three existing datasets of communication exchanges and found that people either reply relatively quickly or they do not reply at all. Despite digital communication having the benefit of being able to be asynchronous, people feel the need to reply quickly or be apologetic if their answer is delayed (Mazmanian, Orlikowski, \& Yates, 2005; Mazmanian et al., 2006). That is because quick responses give non-verbal cues of immediacy and presence, i.e., being constantly available (Kalman, Ravid, Raban, \& Rafaeli, 2006). If we are not constantly available, we feel we need to justify ourselves. In addition, aggravating this problem, some companies are even selling their employees' rapid and sometimes constant (“24/7”) availability as part of the company's services (Mazmanian \& Erickson, 2014). Given the more or less perceived expectations of a need for quick replies at any time, users are often expected to pay attention to their devices and any incoming notifications. Dingler and Pielot (2015) quantified attentiveness towards mobile messaging, analysing logs of mobile messaging notifications and user attentiveness for 42 participants over the course of two weeks. They found that people are attentive to messages for approximately 12.1 hours of the day, with higher peaks during weekdays and evenings. Taking this back to work-home boundary management, the pressures of having to constantly pay attention to work and/or personal communication, even when not currently embodying that role, can become overwhelming (Barley et al., 2011; Kossek et al., 2012; Mazmanian et al., 2006).

\section{Awareness of Work and Personal Availability}


If availability is something that belongs to oneself, the awareness of that availability is instead obtained by those we interact with. Understanding how to manage the two sides of this coin is crucial when taking a social-constructionist approach of boundary management. Awareness of one's availability can be gained in a number of ways: by explicitly asking/being told, by assumption, or by taking notice of the other person's habits. Of relevance, there are specific features in communication platforms that are used to infer one's availability and attentiveness to messages: these are referred to as awareness cues (Oulasvirta et al., 2007; Rice et al., 2017) and can be for example, read receipts, notifications, or online statuses to infer other people's activity (O'Hara et al., 2014). Understanding how people make use of awareness cues is important for work-home boundary management, because it can help identify where conflicts might arise and how to reduce them. Knowing when and how to communicate availability or unavailability can be a useful strategy to help shift between work and personal roles.

The first research to provide an in-depth analysis of the issues around awareness cues in mobile devices was conducted by Oulavirta et al. (2007), who found that participants were able to infer someone's activity (e.g., sleeping), someone's potential availability to engage in some sort of communication (e.g., based on when they were last online), or even social situation (e.g., if two people were in the same location). A substantial body of work has looked at how these cues are used particularly in the work context to infer response times and one's availability (e.g., Avrahami, Fussell, \& Hudson, 2008; Birnholtz, Bi, \& Fussell, 2012; Dourish \& Bellotti, 1992). Since the initial work was published in 2007, the inclusion of awareness cues in instant messaging tools has become widespread. WhatsApp in particular allows users to be notified when a message is sent and delivered, with the use of two separate ticks next to each message. In addition, it displays the last time a user was online, a feature 
that can be disabled. Since that study was published, WhatsApp has added an additional feature: a change in colour (from grey to blue) in the two ticks to notify when a message has been read. In their study of 20 WhatsApp users, O’Hara et al. (2014) uncovered “doings”, i.e., ways of engaging with relationships through IM-like applications. For example, the authors talk about "plausible deniability" and "plausible accounting” when discussing awareness features (i.e., "last seen online" and receipt ticks). They claim that these awareness features are not necessarily perceived as a precursor of interaction and communication —as Nardi, Whittaker and Bradner (2000) argue when discussing the use of IM in the office- but are instead messages per se, which they define as an "encounter of knowing" (i.e., the user gains insight about the interlocutor without having to communicate with him or her) as opposed to an "encounter of communication". These awareness features add temporal properties to a communication, which need to be interpreted based on the interlocutor's habits (e.g., how quickly are they likely to reply). O'Hara and colleagues (2014) explain how, when the communication happens between friends or family, these temporal patterns can be easily explained, but issues of social pressure to respond rise with particular, less intimate, relationships, such as with acquaintances or work colleagues. In these circumstances, knowing that someone has received and read a message can lead to an expectation that a reply will be sent immediately.

As a consequence, user behaviour has evolved as people have become more aware of how their behaviour can trigger these cues to be sent to others. Users therefore adopt strategies to avoid triggering such cues. For example, we found that one of the ways in which smartwatches help people to manage their availability, and therefore their work-home boundaries, is that they enable users to read the text of any incoming message without any 
awareness cues being sent (Cecchinato \& Cox, 2017; Cecchinato et al., 2017). Thus, curating others' awareness of one's availability can help regain control over boundary cross-overs.

Awareness cues are also used by receivers of a message as a way of communicating unavailability, and therefore protecting their personal (or work) time. For example, Birnholtz and colleagues (Birnholtz, Guillory, Hancock, \& Bazarova, 2010; Birnholtz, Hancock, Smith, \& Reynolds, 2012), and Patterson et al. (2008) report strategies to avoid being constantly connected and create boundaries between devices and work and personal roles, for example by marking oneself as "away" or "invisible" on messaging platforms, despite being at their computer. Birnholtz et al. (2010) call these "butler lies", but focused in particular on explicitly verbalized lies or linguistic solutions to overcome the technology design limitations in teenagers (e.g., saying "sorry I just saw you text" when actually it was seen straight away). The authors highlight the importance of being able to manage and coordinate one's unavailability, especially in our always-connected society. These "lies provide a useful window into the broader sociotechnical problem of unavailability and inattention management” (Birnholtz, Hancock et al., 2012, p. 35). Unfortunately, technology can give away the truth without the user necessarily realizing it. For example, automatic read receipts can uncover whether someone has really just read a message or indeed had delayed a reply and verbally lied about it. Ultimately, this emphasizes how managing work-home boundaries through communication technologies requires a multi-pronged effort from individuals and those they interact with (based on what strategies they use and how these are interpreted), organizations (what guidelines and training to they put in place) and interaction designers (how they design technology to support users' boundary preferences). We discuss these aspects in the following final section. 
We started this chapter by looking at how work-home boundaries can be challenged or crossed in either direction and how this can result in either conflicts or enrichment. We then moved on to explore how mobile technology, especially when used within multi-device ecologies, can challenge boundary management, before discussing how communication technologies are used and adopted to manage one's availability and work-home boundaries. Together, this paints a picture of all the complex work required to create, maintain and manage these boundaries, for which support and guidance are often lacking.

Communication and mobile technologies have made it easier to stay connected and thus facilitate an integration between work and personal life. However, Kossek, Lautsch and Eaton (2006) found that segmentation is a strong predictor of wellbeing, consistent with Ashforth et al. (2000), and Hall and Richter (1988), who point out that integration can lead to negative consequences. While creating a sense of detachment from work can help recovery from work stress (Park et al., 2011), segmenting can also be more demanding from a psychological point of view (Ashforth et al., 2000): it is not always as easy to stop thinking or worrying about a personal matter or a work related issue, as it is to disable notifications. Building on initial work looking at physical boundary artefacts (Nippert-Eng, 1996), more attention is being given to the role technology plays in boundary management. Most of these efforts fall under top-down policies and guidelines (e.g., Kossek et al., 2011), but more recently researchers have started to uncover bottom-up strategies that individuals can adopt (e.g., Cousins \& Robey, 2015).

\section{Top-down Boundary Strategies}

One of the ways companies can influence people's boundary strategies is through their own policies. In the past few years, several policies and government precautions have been put in place to in an attempt to help workers better manage work-home boundaries 
(Cecchinato, Fleck, Brid, \& Cox, 2015). These build upon family-friendly programs (e.g., shared parental leave) and manifest an acknowledgement on the institutions' side of personal life values, to help lessen the effects of role conflict. Additionally, companies that pay for employees' devices or have Bring Your Own Device (BYOD) policies are implicitly (or even explicitly in some cases) suggesting who is in control of boundary permeation (Grevet, 2014). In the first case (buying devices for employees), an employee may feel he or she is expected to be available around the clock; in the second case (adopting BYOD policies) workers might feel legitimised to take personal communications while at work (Fleck et al., 2015; Grevet, 2014). More recently, Boswell and collaborators have proposed a series of recommendations for organisations who want to help their employees manage after hourwork communications (Boswell et al., 2016).

A variety of organisations have adopted policies with the aim of supporting workhome boundary segmentation. For example, in April 2014 officials from the Swedish city Gothenburg launched a trial policy by adopting six-hour working days, expecting the mental and physical state of their employees to improve and their productivity to increase (Crew, 2015; Gee, 2014). The experiment lasted two years and ended in early 2017: the positive results of employees feeling healthier and more productive, however, were met with some scalability concerns by the government (Alderman, 2017). Other European countries have considered similar measures. For example, Germany's labour minister has been considering an "anti-stress" law as a measure to reduce mental health issues connected to the constantly available paradigm (i.e., checking emails after working hours) and commissioned an investigation to determine binding thresholds (Stuart, 2014). More recently, the French government introduced a law on the "right to disconnect" at the beginning of 2017, whereby employers should negotiate with employees how to reduce work intruding in their personal 
life, sanctioning companies who fail to clearly state what is expected of employees out of hours (Agence France - Presse, 2016).

All these examples assume a one-size fits all solution. However, how one manages work-home boundaries depends on several factors. To this end, we compared different professional groups within the same university and found that how email is managed across accounts and devices varies greatly based on personal preference, but also professional differences between staff in different roles (Cecchinato, Cox, et al., 2015b). As mentioned previously, each role comes with certain expectations and resources and rather than suggesting that all employees should stop checking emails after a certain hour, researchers have suggested offering training for employees to manage resources and expectations more consciously and effectively (Jahn, Klesel, Lemmer, \& Weigel, 2016).

\section{Bottom-up Boundary Strategies}

Depending on one's boundary preference for integration or segmentation, different boundary strategies may be adopted. However, individualised strategies are crafted in a dynamic and flexible way (Sturges, 2012), making it hard to know which ones to adopt. As emphasised by Chen and Karahanna (2014, p. 31), "given that cross-domain technologymediated interruptions are unavoidable for today's knowledge workers, a concerted effort is needed by technology designers, organizations, and knowledge workers to provide tools and techniques to alleviate negative effects". Some researchers have started to at least identify types of boundary strategies and provide some actionable knowledge for individuals.

Christena Nippert-Eng (1996) identified interesting behaviours and artefacts used for managing boundaries, like having separate calendars or key chains for work and personal reasons. Kreiner et al. (2009) identified boundary work tactics pertinent to behavioural, temporal, physical, and communicative aspects. Of particular interest are the communicative 
tactics, identified as "setting expectations" and "confronting violations". Despite this work being published in 2009 when mobile technology was already mainstream, there is very little mention about the role technology plays in creating and using these boundary tactics. The authors labelled a type of behavioural tactic as "leveraging on technology" but did not provide detailed examples of how their participants actually leveraged technology, other than relying on caller ID and voicemail. Olson-Buchanan and Boswell (2006) discuss how technology can be used to set appropriate boundaries. They found that when fewer boundaries around the use of communication technology during non-work time are set, more work interference on non-work occurs compared to when boundaries are put in place. Golden and Geisler (2007) were among the first to study the use of a device as a boundary management strategy. They interviewed 42 users about their use of a PDA (Personal Digital Assistant) and found that participants used their devices to support their boundary style preference - whether integrating, segregating, or transcending boundaries between work and home. More recently, Cousins and Robey (2015) identified a series of tactics that can be put in place to manage psychological boundaries, including (1) designating certain rules for technology (e.g., having one phone for personal use and one for work use), (2) setting permeating rules (e.g., logging out of IM platforms when switching domain), or (3) creating connection/disconnection rules (e.g., turning off devices after a certain hour).

While the strategies presented in the previous paragraph offer a classification of boundary management behaviours, they do not provide actionable strategies that other users can pick up and use. To this end, Köffer, Anlauf, Ortbach and Niehaves $(2015$, p. 1) identified three strategies for boundary integration, and three for segmentation. These primarily refer to the use of company devices for only work or both work and personal reasons, and similarly the use of personal devices just for personal use or also for work 
purposes. The authors emphasised the number of issues that users still encountered in fulfilling their boundary preferences, and in particular how those who tended to integrate work and personal life included also users who would prefer to segment the two domains but were not successful because they were unable to manage their technology. Other actionable strategies come from Jahn et al. (2016), who classified IT-related tactics based on how these tactics are put in place using technology: they can be automated (e.g., allowing automatic push notifications) or implemented manually (e.g., pulling information as a result of disabled notifications). Finally, Cecchinato and colleagues found that communication technology can be used to create microboundaries, i.e. strategies "to limit the impact of micro-role transitions caused by cross-domain technology mediated interruptions" (Cecchinato, Cox et al., 2015b, p. 3997). These strategies can be used to set social microboundaries, (e.g., disabling notifications when out for dinner); temporal microboundaries (e.g., setting restrictions on when certain apps or websites can be accessed); digital microboundaries (e.g., using separate applications to check work and personal emails); and physical microboundaries (e.g., taking off a smartwatch as a symbol of disconnecting from work) (Cecchinato et al., 2017).

Ultimately, microboundaries can be used by interaction designers and individuals as a way to introduce a designed friction when interacting with technology. These frictions could be as simple as a pop-up notification reminding a user of their intentions not to check work emails at certain times or in certain locations. Rather than encouraging seamless interactions, we have proposed the idea that for interactions to introduce small hurdles (or designed frictions), that can help users stop and reflect about what they are doing. In turn, this can help foster more mindful interactions with technology (Cox, Gould, Cecchinato, Iacovides, \& Renfree, 2016). As technologies become more ubiquitous, we call for more work to explore how technology should be designed to support individuals' boundary management practices. 


\section{Conclusions}

Communication technologies have increased how easily, how frequently, and how many boundary transitions can occur on a daily basis between one's several life roles. This can be problematic because disconnection from work is important for recovery from workrelated stress. Similarly, to ensure focus and productivity, it is important to ensure some separation from personal matters while at work. Given the large number of people suffering from work-related stress, it is crucial to understand how individuals, policy-makers, and practitioners can help support better boundary management practices and thus better recovery. In this chapter, we have reviewed a large body of research, pointing out new trends that bring together two fields — occupational psychology and $\mathrm{HCI}$ - by combining literature on boundary theory, multi-device implications, and computer-mediated communication use. The two fields offer complementary views on the use of technology and its impact on our daily lives. By taking a social-constructionist view of technology, and particularly relying on one of the four concepts of SCOT — interpretive flexibility — we have emphasised how communication technologies can both support as well as challenge home-work boundary management. This approach has allowed us to identify strategies that individuals and organisations can rely on when socially constructing the boundaries between work and home domains. 
Boundary Management and Communication Technologies, p-28

\section{References}

Agence France - Presse. (2016). French workers win legal right to avoid checking work email out-of-hours. The Guardian. Retrieved 18 February 2018, from https://www.theguardian.com/money/2016/dec/31/french-workers-win-legal-right-toavoid-checking-work-email-out-of-hours

Alderman, L. (2017). In Sweden, happiness in a shorter workday can't overcome the cost. The New York Times. Retrieved 18 February 2018, from https://www.nytimes.com/2017/01/06/business/sweden-work-employmentproductivity-happiness.html?mtrref=query.nytimes.com

Allen, T. D. (2013). The work-family role interface: a synthesis of the research from industrial and organizational psychology. In I. B. Weiner (Ed.), Handbook of psychology (2nd ed.) (pp. 698-718). Wiley \& Sons, Inc.

Amstad, F. T., Meier, L. L., Fasel, U., Elfering, A., \& Semmer, N. K. (2011). A metaanalysis of work-family conflict and various outcomes with a special emphasis on cross-domain versus matching-domain relations. Journal of Occupational Health Psychology, 16(2), 151-169.

Ashforth, B., Kreiner, G. E., \& Fugate, M. (2000). All in a day’s work: boundaries and micro-role transitions. Academy of Management Review, 25(3), 472-491.

Avrahami, D., Fussell, S. R., \& Hudson, S. E. (2008). IM waiting: timing and responsiveness in semi-synchronous communication. In Proceedings of the 2008 ACM conference on computer supported cooperative work (pp. 285-294). Florence: ACM.

Axtell, C., Hislop, D., \& Whittaker, S. (2008). Mobile technologies in mobile spaces:

Findings from the context of train travel. International Journal of Human-Computer Studies, 66(12), 902-915. https://doi.org/10.1016/j.ijhcs.2008.07.001 
Barley, S. R., Meyerson, D. E., \& Grodal, S. (2011). E-mail as a source and symbol of stress. Organization Science, 22(4), 887-906. https://doi.org/10.1287/orsc.1100.0573

Birnholtz, J., Bi, N., \& Fussell, S. (2012). Do you see that I see? Effects of perceived visibility on awareness checking behavior. In Proceedings of the SIGCHI conference on human factors in computing systems (pp. 1765-1774). Austin, TX: ACM

Birnholtz, J., Guillory, J., Hancock, J., \& Bazarova, N. (2010). “On my way ”: Deceptive texting and interpersonal awareness narratives. In Proceedings of the 2010 ACM conference on computer supported cooperative work (pp. 1-4). Savannah, GA: ACM.

Birnholtz, J., Hancock, J., Smith, M., \& Reynolds, L. (2012). Understanding unavailability in a world of constant connection. Interactions, 19(5), 32.

Bittman, M., Brown, J. E., \& Wajcman, J. (2009). The mobile phone, perpetual contact and time pressure. Work, Employment and Society, 23(4), 673-691.

Bødker, S. \& Klokmose, C. N. (2012). Dynamics in artifact ecologies. In Proceedings of the 7th Nordic conference on human-computer interaction: Making sense through design (pp. 448-457). Copenhagen: ACM.

Boswell, W. R. \& Olson-Buchanan, J. B. (2007). The use of communication technologies after hours: The role of work attitudes and work-life conflict. Journal of Management, 33(4), 592-610.

Boswell, W. R., Olson-Buchanan, J. B., Butts, M. M., \& Becker, W. J. (2016). Managing “after hours" electronic work communication. Organizational Dynamics, 45(4), 291297.

Brown, B. \& O’Hara, K. (2003). Place as a practical concern of mobile workers. Environment and Planning A, 35(9), 1565-1587. 
Cecchinato, M. E. \& Cox, A. L. (2017). Smartwatches: Digital handcuffs or magic bracelets? Computer, 50(4), 106-109.

Cecchinato, M. E., Cox, A. L., \& Bird, J. (2015a). Smartwatches: The good, the bad and the ugly? In Proceedings of the 33rd annual ACM conference extended abstracts on human factors in computing systems (pp. 2133-2138). Seoul: ACM.

Cecchinato, M. E., Cox, A. L., \& Bird, J. (2015b). Working 9-5? Professional differences in email and boundary management practices. In Proceedings of the SIGCHI conference on human factors in computing system (pp. 3989-3998). Seoul: ACM.

Cecchinato, M. E., Cox, A. L., \& Bird, J. (2017). Always on(line)? User experience of smartwatches and their role within multi-device ecologies. in proceedings of the 2017 CHI conference on human factors in computing systems (pp. 3557-3568). Denver, CO: ACM.

Cecchinato, M. E., Fleck, R., Brid, J., \& Cox, A. L. (2015). Online vs. Offline: Implications for Work Identity. In CHI 2015 workshop: Between the lines: Reevaluating the online/offline binary (pp. 1-6). Seoul: ACM.

Cecchinato, M. E., Sellen, A., Shokouhi, M., \& Smyth, G. (2016). Finding email in a multiaccount, multi-device world. In Proceedings of the ACM conference on human factors in computing systems (pp. 1200-1210). San Jose, CA: ACM.

Chen, A. \& Karahanna, E. (2014). Boundaryless technology: Understanding the effects of technology-mediated interruptions across the boundaries between work and personal life. AIS Transactions on Human-Computer Interaction, 6(2), 16-36.

Cho, J., Ramgolam, D. I., Schaefer, K. M., \& Sandlin, A. N. (2011). The rate and delay in overload: An investigation of communication overload and channel synchronicity on 
identification and job satisfaction. Journal of Applied Communication Research, $39(1), 38-54$.

Church, K. \& de Oliveira, R. (2013). What's up with WhatsApp? Comparing mobile instant messaging behaviors with traditional SMS. 15th international conference on humancomputer interaction with mobile devices and services (pp. 352-361). Munich: ACM.

Clark, S. C. (2000). Work/family border theory: A new theory of work/family balance. Human Relations, 53(6), 747-770.

Cousins, K. C. \& Robey, D. (2015). Managing work-life boundaries with mobile technologies. Information Technology \& People, 28(1), 34-71.

Cox, A. L., Gould, S., Cecchinato, M. E., Iacovides, I., \& Renfree, I. (2016). Design frictions for mindful interactions: The case for microboundaries. In CHI extended abstracts on human factors in computing systems (pp. 1389-1397). San Jose, CA: ACM.

Crew, B. (2015). Sweden is shifting to a 6-hour work day. Retrieved 18 February 2018, from https://www.sciencealert.com/sweden-is-shifting-to-a-6-hour-workday

Dearman, D. \& Pierce, J. S. (2008). It's on my other Computer!: Computing with multiple devices. In Proceedings of the SIGCHI conference on human factors in computing systems (pp. 767-776). Florence: ACM.

Dery, K., Kolb, D., \& MacCormick, J. (2014). Working with connective flow: How smartphone use is evolving in practice. European Journal of Information Systems, $23(5), 558-570$.

Diaz, I., Chiaburu, D. S., Zimmerman, R. D., \& Boswell, W. R. (2012). Communication technology: Pros and cons of constant connection to work. Journal of Vocational Behavior, 80(2), 500-508. 
Dingler, T. \& Pielot, M. (2015). I'll be there for you: Quantifying attentiveness towards mobile messaging. In Proceedings of the international conference on humancomputer interaction with mobile devices and services (pp. 1-5). Copenhagen: ACM.

Dourish, P. (2006). Re-Space-ing place: 'Place' and 'Space' ten years on. In Proceedings of the 200620 th anniversary conference on computer supported cooperative work (pp. 299-308). Banff, AB: ACM.

Dourish, P. \& Bellotti, V. (1992). Awareness and coordination in shared workspaces. In Proceedings of the ACM conference on computer-supported cooperative work (pp. 107-114). Toronto: ACM.

Farnham, S. D. \& Churchill, E. F. (2011). Faceted identity, faceted lives: Social and technical issues with being yourself online. In Proceedings of the ACM conference on computer-supported cooperative work (pp. 359-368). Hangzhou, China: ACM.

Fleck, R., Cox, A. L., \& Robison, R. A. V. (2015). Balancing boundaries: Using multiple devices to manage work-life balance. In Proceedings of the ACM conference on human factors in computing systems (pp. 3985-3988). Seoul: ACM.

Fortunati, L. (2002). The mobile phone: Towards new categories and social relations. Information, Communication \& Society, 5(4), 513-528.

Gee, O. (2014). Swedes to give six-hour workday a go. The Local. Retrieved 18 February 2018, from https://www.thelocal.se/20140408/swedish-workers-to-test-six-hourwork-days

Goffman, E. (1959). The presentation of self in everyday life. Penguin.

Golden, A. G. \& Geisler, C. (2007). Work-life boundary management and the personal digital assistant. Human Relations, 60(3), 519-551. 
Grant, M. J. \& Booth, A. (2009). A typology of reviews: An analysis of 14 review types and associated methodologies. Health Information and Libraries Journal, 26(2), 91-108.

Greenhaus, J. \& Powell, G. N. (2006). When work and family are allies: A theory of workfamily enrichment. Academy of Management Review, 31(1), 77-92.

Grevet, C. (2014). Managing the work-home boundary in a BYOD (Bring Your Own Device) culture. In MobileHCI'14 workshop on socio-technical systems and work-home boundaries (pp. 1-4). Toronto: ACM.

Hall, D. T. \& Richter, J. (1988). Balancing work life and home life: What can organizations do to help? Academy of Management Executive, 2(3), 213-223.

Harrison, S. \& Dourish, P. (1996). Re-place-ing space. In Proceedings of the ACM conference on computer supported cooperative work (pp. 67-76). Boston: ACM.

Heider, F. (1946). Attitudes and cognitive organization. The Journal of Psychology, 21(1), 107-112. https://doi.org/10.1080/00223980.1946.9917275

HSE (2017). Tackling work-related stress using the Management Standards approach (Workbook). Health and Safety Executive. Retrieved 18 February 2018, from http://www.hse.gov.uk/pubns/wbk01.htm

Jahn, K., Klesel, M., Lemmer, K., \& Weigel, A. (2016). Individual boundary management: An empirical investigation on technology-related tactics. In PACIS Proceedings (pp. 268-280). Taiwan: AIS.

Kalman, Y. M. (2016). Why do we blame information for our overload? In D. I. Ballard \& M. S. McGlone (Eds.), Work pressures: New agendas in communication (pp. 45-62). New York: Routledge. 
Kalman, Y. M. \& Rafaeli, S. (2005). Email chronemics : Unobtrusive profiling of response times. In Proceedings of the 38th annual Hawaii international conference on system sciences (pp. 1-10). Big Island, HI: IEEE.

Kalman, Y. M., Ravid, G., Raban, D. R., \& Rafaeli, S. (2006). Pauses and response latencies: A chronemic analysis of asynchronous CMC. Journal of Computer-Mediated Communication, 12(1), 1-23.

Karlson, A. K., Meyers, B. R., Jacobs, A., Johns, P., \& Kane, S. (2009). Working overtime: Patterns of smartphone and PC usage in the day of an information worker. In International conference on pervasive computing (pp. 398-405). Orlando, FL: ACM.

Kawsar, F. \& Brush, A. (2013). Home computing unplugged: Why, where and when people use different connected devices at home. In Proceedings of the 2013 ACM international joint conference on pervasive and ubiquitous computing (pp. 627-636). Zurich: ACM.

Klein, H. K. \& Kleinman, D. L. (2002). The social construction of technology: Structural considerations. Science, Technology, \& Human Values, 27(1), 28-52.

Köffer, S., Anlauf, L., Ortbach, K., \& Niehaves, B. (2015). The intensified blurring of boundaries between work and private life through IT consumerization. In Proceedings of the 23rd European conference on information systems (ECIS 2015) (pp. 1-17). Münster: AIS.

Kossek, E. E., Baltes, B. B., \& Matthews, R. A. (2011). How work-family research can finally have an impact in organizations. Industrial and Organizational Psychology, 4(03), 352-369. 
Kossek, E. E., Lautsch, B. A., \& Eaton, S. C. (2006). Telecommuting, control, and boundary management: Correlates of policy use and practice, job control, and work-family effectiveness. Journal of Vocational Behavior, 68(2), 347-367.

Kossek, E. E., Ruderman, M. N., Braddy, P. W., \& Hannum, K. M. (2012). Work-nonwork boundary management profiles: A person-centered approach. Journal of Vocational Behavior, 81(1), 112-128.

Kreiner, G. E., Hollensbe, E. C., \& Sheep, M. L. (2009). Balancing borders and bridges: Negotiating the work-home interface via boundary work tactics. Academy of Management Journal, 52(4), 704-730.

Matthews, T., Pierce, J., Road, H., Jose, S., \& Tang, J. (2009). No smartphone is an island: The impact of places, situation and other device on smart phone use. IBM RJ10452., $10452,1-10$.

Mazmanian, M. \& Erickson, I. (2014). The product of availability: Understanding the economic underpinnings of constant connectivity. In Proceedings of the SIGCHI conference on human factors in computing systems (pp. 763-772). Toronto: ACM.

Mazmanian, M., Orlikowski, W. J., \& Yates, J. (2005). CrackBerrys: Exploring the social implications of ubiquitous wireless email devices. In Designing ubiquitous information environments: Socio-technical issues and challenges (pp. 337-343). Boston, MA: Springer.

Mazmanian, M., Yates, J., \& Orlikowski, W. (2006). Ubiquitous email: Individual experiences and organizational consequences of Blackberry use. In Academy of Management proceedings, Meeting abstract supplement, 1, D1-D6. Briarcliff Manor, NY 10510: Academy of Management. 
Moen, P. (2011). From 'work-family' to the 'gendered life course' and 'fit': Five challenges to the field. Community, Work, \& Family, 14(1), 81-96.

Nardi, B. A., Whittaker, S., \& Bradner, E. (2000). Interaction and outeraction: Instant messaging in action. In Proceedings of the 2000 ACM conference on computer supported cooperative work (pp. 79-88). Philadelphia, PA: ACM.

Nippert-Eng, C. (1996). Calendars and keys: The classification of "home" and "work". Sociological Forum, 11(3), 563-582.

Nouwens, M., Griggio, C. F., \& Mackay, W. E. (2017). WhatsApp is for family, Messenger is for friends: Communication places in app ecosystems. In Proceedings of the CHI conference on human factors in computing systems (pp. 727-735). Denver, CO:

\section{ACM.}

O’Hara, K. P., Massimi, M., Harper, R., Rubens, S., \& Morris, J. (2014). Everyday dwelling with WhatsApp. In Proceedings of the 17th ACM conference on computer supported cooperative work \& social computing (pp. 1131-1143). Baltimore, MA: ACM.

Olson-Buchanan, J. B., \& Boswell, W. R. (2006). Blurring boundaries: Correlates of integration and segmentation between work and nonwork. Journal of Vocational Behavior, 68(3), 432-445.

Oulasvirta, A., Petit, R., Raento, M., \& Sauli, T. (2007). Interpreting and acting on mobile awareness cues. Human-Computer Interaction, 22(October), 97-135.

Park, Y., Fritz, C., \& Jex, S. M. (2011). Relationships between work-home segmentation and psychological detachment from work: The role of communication technology use at home. Journal of Occupational Health Psychology. 16(4), 457-467 
Patterson, D. J., Baker, C., Ding, X., Kaufman, S. J., Liu, K., \& Zaldivar, A. (2008). Online everywhere: Evolving mobile instant messaging practices. In Proceedings of the 10th international conference on ubiquitous computing (pp. 64-73). Seoul: ACM.

Pew Research. (2018). Demographics of mobile device ownership and adoption in the United States. Pew Research Center. Retrieved 18 February 2018, from http://www.pewinternet.org/fact-sheet/mobile/

Pielot, M., Church, K., \& de Oliveira, R. (2014). An in-situ study of mobile phone notifications. In Proceedings of the international conference on human-computer interaction with mobile devices \& services (pp. 233-242). Toronto: ACM.

Pyöriä, P. (2005). The concept of knowledge work revisited. Journal of Knowledge Management, 9(3), 116-127.

Radicati Group. (2015a). Instant messaging statistics report, 2015-2019. Retrieved 18 February 2018 from https://www.radicati.com/wp/wpcontent/uploads/2015/03/Instant-Messaging-Statistics-Report-2015-2019-ExecutiveSummary.pdf

Radicati Group. (2015b). Mobile Statistics Report, 2015-2019. Retrieved 18 February 2018 from https://www.radicati.com/wp/wp-content/uploads/2015/02/Mobile-StatisticsReport-2015-2019-Executive-Summary.pdf

Rice, R. E. (2017). Flexwork, boundaries, and work-family conflicts: How ICTs and work engagement influence their relationship. In G. Hertel, D. Stone, R. D. Johnson, \& J. Passmore (Eds.), Handbook of the psychology of the internet at work (pp. 175-193). London, UK: Wiley Blackwell Industrial \& Organizational Psychology Series. 
Rice, R. E., Evans, S. K., Pearce, K. E., Sivunen, A., Vitak, J., \& Treem, J. W. (2017). Organizational media affordances: Operationalization and associations with media use: organizational media affordances. Journal of Communication, 67(1), 106-130.

Roche, H. G. (2015). Managing work and life: The impact of framing. Unpublished Ph.D. Dissertation. Seattle Pacific University. http://digitalcommons.spu.edu/iop_etd/4/

Santosa, S. \& Wigdor, D. (2013). A field study of multi-device workflows in distributed workspaces. In Proceedings of the 2013 ACM international joint conference on pervasive and ubiquitous computing (pp. 63-72). Zurich: ACM.

Shen, J., Brdiczka, O., \& Ruan, Y. (2013). A comparison study of user behavior on Facebook and Gmail. Computers in Human Behavior, 29(6), 2650-2655.

Specht, B. (2018). The 2017 email client market share [Infographic]. Litmus Software, Inc. Retrieved 19 February 2018, from https://litmus.com/blog/the-2017-email-clientmarket-share-infographic

Stuart, K. (2014). German minister calls for anti-stress law ban on emails out of office hours | Technology. The Guardian. Retrieved 18 February 2018, from https://www.theguardian.com/technology/2014/aug/29/germany-anti-stress-law-banon-emails-out-of-office-hours

Sturges, J. (2012). Crafting a balance between work and home. Human Relations, 65(12), 1539-1559. https://doi.org/10.1177/0018726712457435

The NPD Group. (2017). Smartwatch ownership expected to increase nearly 60 percent into 2019. Retrieved 18 February 2018 from https://www.npd.com/wps/portal/npd/us/news/press-releases/2017/us-smartwatchownership-expected-to-increase-nearly-60-percent-into-2019/ 
Turel, O. \& Serenko, A. (2010). Is mobile email addiction overlooked? Communications of the ACM, 53(5), 41.

Williams, K. J., Suls, J., Alliger, G. M., Learner, S. M., \& Wan, C. K. (1991). Multiple role juggling and daily mood states in working mothers: An experience sampling study. Journal of Applied Psychology, 76(5), 664-674. 